\title{
Billroth I Technique Application after Resection of Gastric Leiomyoma in a Dog
}

\author{
Paulo Geovane de Cantuário Ferreira', Leonardo Inocêncio Cunha', Júlia Caroline Assis Machado', \\ Maysa Alves Macedo', Luiz Caian Stolf², Daniel Barbosa da Silva' \& Saulo Humberto de Ávila Filho'
}

\begin{abstract}
Background: Gastric neoplasia is rare, corresponding to less than $1 \%$ of cases, with a lower prevalence of those involving smooth muscle tissues. In these cases, clinical signs worsen in the occurrence of pyloric obstruction, leading to clinical manifestations such as chronic emesis. The exeresis of the neoplasm is promoted as a therapeutic measure to reestablish gastrointestinal flow. There partial gastrectomy followed by gastroduodenal anastomosis, using the Billroth I technique, is among the available surgical techniques. The therapeutic success of the Billroth I technique after pylorectomy was reported in a dog with gastric leiomyoma.

Case: A 9-year-old male Poodle dog, weighing $9.5 \mathrm{~kg}$, was referred for clinical evaluation with a history of chronic vomiting starting three months ago, progressive weight loss, and melena, previously treated by another Veterinarian as idiopathic gastroenteritis. The physical evaluation of the animal showed a state of normal consciousness, body score 4/9, pale ocular and oral mucous membranes, respiratory rate $20 \mathrm{mpm}$, heart rate $166 \mathrm{bpm}$, a rectal temperature of $37.9^{\circ} \mathrm{C}$, and dehydration degree of $8.0 \%$. Blood count showed normocytic normochromic anemia and leukocytosis with shift to the right. Radiographic and endoscopic examinations were not noteworthy. Endoscopic biopsy after a histopathological evaluation showed no cellular or tissue atypia. On the other hand, abdominal ultrasound assessment revealed thickening with loss of echotexture and definition of the muscular layer of the gastric wall, pyloric and duodenum region compatible with benign antral muscle hypertrophy and/or pyloric neoplasia. The animal worsened 5 days after the initial treatment, with progressive episodes of emesis and melena, opting for an exploratory laparotomy. A mass of firm consistency measuring approximately $2.5 \times 6.0 \mathrm{~cm}$ in diameter was found in the pyloric region, opting for a pylorectomy. The excised fragment was sent for histopathological examination. Then, gastroduodenal anastomosis was performed using the Billroth I technique. After the surgery, a pasty diet was introduced orally, without using gastroenteric tubes. Dry food was offered 10 days after the surgical procedure. The animal returned for clinical reevaluation on the fifteenth day and was clinically well. Histopathological examination revealed a diagnosis of gastric leiomyoma.

Discussion: The casuistry of gastric neoplasia in dogs has a low incidence, with an occurrence of less than $1 \%$, with adenocarcinoma being the most common type. However, there are less frequent reports of other gastric neoplasia, such as smooth muscle tumors. Abdominal ultrasonography is indicated for the diagnosis of gastrointestinal changes, proof of which ultrasonography was of paramount importance in this case. The surgical procedure of pylorectomy guaranteed a margin of one centimeter, meeting the principles of oncological surgery. Absorbable monofilament suture materials are the choice for the synthesis stage in hollow organs, being used in this case. The most-reported expected complications of gastrointestinal surgeries aiming at removing neoplasms are vomiting, anorexia, melena, hematochezia, hematemesis, necrosis with anastomotic ulceration, and, consequently, septic peritonitis, which were not reported in this case. The life expectancy of patients with gastric neoplasia is quite variable, with longer survival in cases of benign neoplasia. Therefore, the type of neoplasia in this case, together with the appropriate choice of therapy and the appropriate performance of the technique, was important for the good result achieved.
\end{abstract}

Keywords: gastrectomy, gastroduodenoanastomosis, gastroenteroanastomosis, neoplasm, surgery. 


\section{INTRODUCTION}

Advances in diagnostic methods and increased life expectancy of dogs have led to an increase in the diagnosis of neoplasms [19].

Gastric neoplasia is rare compared to other neoplasms that affect dogs, corresponding to less than $1 \%$ of cases [13]. Among them, adenocarcinoma is the most frequent, but with the lowest prevalence when involving smooth muscle [5,12]. A pyloric obstruction may occur depending on the location of the gastric neoplasia, compromising gastric emptying and culminating in clinical signs $[12,15,18]$.

Ultrasound, endoscopy, tomography, and magnetic resonance stand out exams of choice in the diagnosis of gastric neoplasia [3,14]. The definitive diagnosis in cases of neoplasia is only obtained through histopathological examination, regardless of the used diagnostic imaging method [12].

Antropyloric hyperplasia, fungal granulomatous disease, eosinophilic granulomas, and foreign bodies must be included as a differential diagnosis of gastric neoplasia [12].

The Billroth I technique, which consists of gastroduodenal anastomosis, is a possibility among the surgical techniques applied to the gastrointestinal system, preserving the bile and pancreatic ducts and being performed after a pylorectomy $[7,11,17]$.

The prognosis depends on the histological type of neoplasia, involved area, impairment of pancreatic and bile ducts, and factors related to the patient, such as age, clinical status, and comorbidities $[7,16]$.

The objective was to report the success of the Billroth I technique after pylorectomy to remove gastric leiomyoma in a dog to encourage the use of the anastomosis technique more frequently.

\section{CASE}

A 9-year-old male Poodle dog, weighing 9.5 $\mathrm{kg}$, was referred for clinical evaluation with a history of chronic vomiting started 3 months before. During this period, there was an increase in the frequency and content present in vomiting, as well as progressive weight loss, in addition to melena. Moreover, the animal had been previously consulted to a Veterinary, who prescribed ranitidine hydrochloride ${ }^{1}$ and omeprazole ${ }^{2}$ both orally, but without effective success, although a slight improvement was noticed, being considered a case of idiopathic gastroenteritis.
The physical evaluation showed that the animal was in a normal state of consciousness, body score 4/9, and pale ocular and oral mucous membranes. Additionally, a respiratory rate of $20 \mathrm{mpm}$ and tachycardia were obtained, totaling $166 \mathrm{bpm}$. There was also a rectal temperature of $37.9^{\circ} \mathrm{C}$ and a dehydration degree of $8.0 \%$ was clinically estimated. Finally, no lymph node was considered enlarged during the palpation stage.

Blood count, abdominal and thoracic radiography, upper digestive endoscopy, and abdominal ultrasound were requested for investigative purposes. The blood count showed normocytic normochromic anemia (3.51 million/ $\mu \mathrm{L}$ of red cells) and leukocytosis with shift to the right.

Radiographic and endoscopic examinations revealed no noticeable alterations. A biopsy of the gastric mucosa was also performed. This material showed no cellular or tissue atypia but after histopathological evaluation.

On the other hand, abdominal ultrasound assessment revealed thickening with loss of echotexture and definition of the muscular layer of the gastric wall, pyloric and duodenum region, compatible with benign antral muscle hypertrophy and/or pyloric neoplasia (Figure 1).

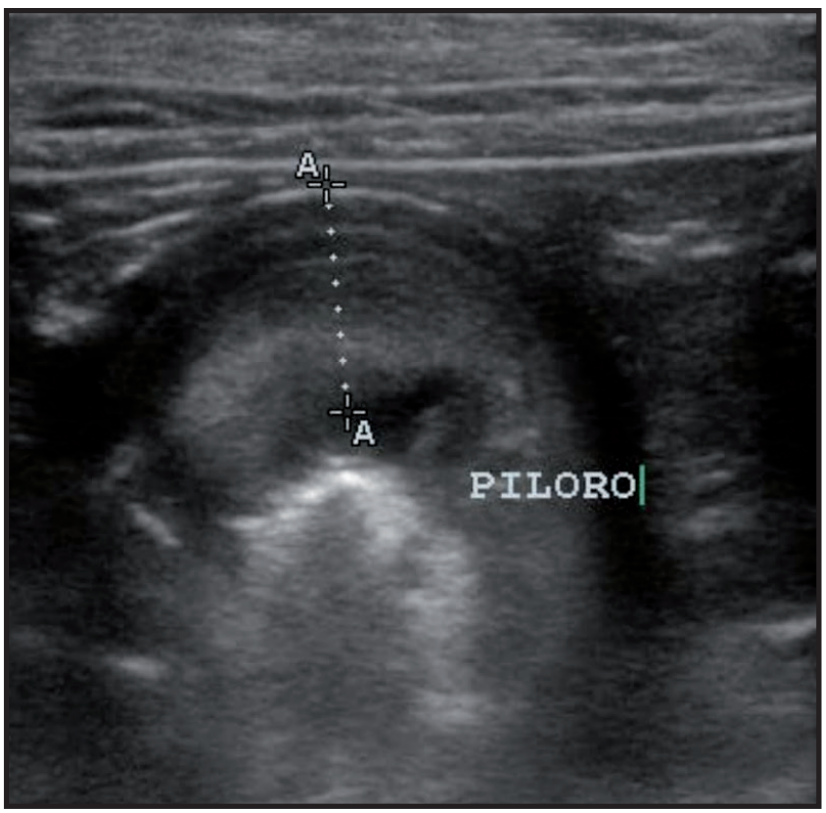

Figure 1. Abdominal ultrasound of a poodle weighing $9.5 \mathrm{~kg}$ showing thickening, with loss of echotexture and definition of the muscular layer of the gastric wall, pyloric region.

The animal worsened 5 days after the initial treatment, with progressive episodes of emesis and melena. In addition to the clinical worsening, there was a negative evolution in the hematological condition, with worsening of anemia and increased leukocytosis. 
Maropitant citrate ${ }^{3}(0.1 \mathrm{mg} / \mathrm{kg}, \mathrm{SC})$ was applied as an antiemetic therapy at that time.

An exploratory laparotomy was chosen considering the worsening of the clinical and hematological condition and ultrasound alteration. The animal was anesthetized to allow the surgery to be performed. Pre-anesthetic medication was started using butorphanol ${ }^{4}$ $(0.2 \mathrm{mg} / \mathrm{kg})$ and acepromazine ${ }^{4}(0.02 \mathrm{mg} / \mathrm{kg})$, intramuscularly. Anesthetic induction was performed using diazepam $^{5}(0.5 \mathrm{mg} / \mathrm{kg})$, followed by propofol ${ }^{5}(3.0 \mathrm{mg} / \mathrm{kg})$, intravenously. Ampicillin ${ }^{4}(22.0 \mathrm{mg} / \mathrm{kg})$, metronidazole ${ }^{6}$ $(15.0 \mathrm{mg} / \mathrm{kg})$, dipyrone ${ }^{4}(25.0 \mathrm{mg} / \mathrm{kg})$, and meloxican ${ }^{7}$ $(0.1 \mathrm{mg} / \mathrm{kg})$ were also administered intravenously during the trans-surgical. Subsequently, orotracheal intubation was performed using a cuffed tube. In turn, anesthetic maintenance was performed with isofluorane ${ }^{5}$ vaporized diluted in $100 \%$ oxygen, using an anesthesia machine with a semi-closed system with gas rebreathing. The animal was maintained on assisted spontaneous ventilation during the surgical procedure.

Surgery started once the surgical anesthetic plan and stage, antisepsis, and preparation of the operative field and surgical team were guaranteed. For this, a median pre-umbilical celiotomy was performed. A mass of firm consistency, measuring approximately $2.5 \times 6.0$ $\mathrm{cm}$ in diameter, was found in the pyloric region once the access to the abdominal cavity was achieved. Then, the stomach was isolated from other abdominal organs, using surgical compresses moistened with heated Ringer's lactate solution ${ }^{8}$. Fixation points were placed to assist in manipulating the stomach. The exeresis of the mass was performed by pylorectomy, using four preventively applied doyen forceps, two cranial and two caudal to the mass. The mas was excised to guarantee a free margin of $1 \mathrm{~cm}$ in all directions. In addition, the excised fragment was placed in a $10.0 \%$ formalin solution and sent for histopathological examination.

Subsequently, the gastroduodenal anastomosis was performed using the Billroth I technique. The gastroduodenostomy was completed by applying two suture planes (simple interrupted followed by Lambert interrupted), both with polydioxanone $4.0^{9}$ thread (Figure 2). The omentalization was performed after suturing, followed by washing with heated Ringer's lactate solution ${ }^{8}$ and, consecutively, drying the abdominal cavity.

The cavity was closed after aspiration. For this, the muscular plane was approximated using polydioxanone $2.0^{9}$ thread, with a Ford interlocking suture pattern. Subcutaneous tissue reduction was performed using poliglecaprone $253.0^{9}$ thread in a zigzag pattern. Finally, a simple interrupted suture was applied for dermorraphy using nylon $4.0^{10}$ thread.

After surgery, the patient remained hospitalized for $72 \mathrm{~h}$, being monitored periodically. During the hospitalization period, the animal received intravenously cephalothin $^{11}$ (30.0 mg/kg/BID), metronidazole ${ }^{6}$ (15.0 $\mathrm{mg} / \mathrm{kg} / \mathrm{BID})$, dipyrone ${ }^{4}$ (25.0 mg/kg/TID), and melo-

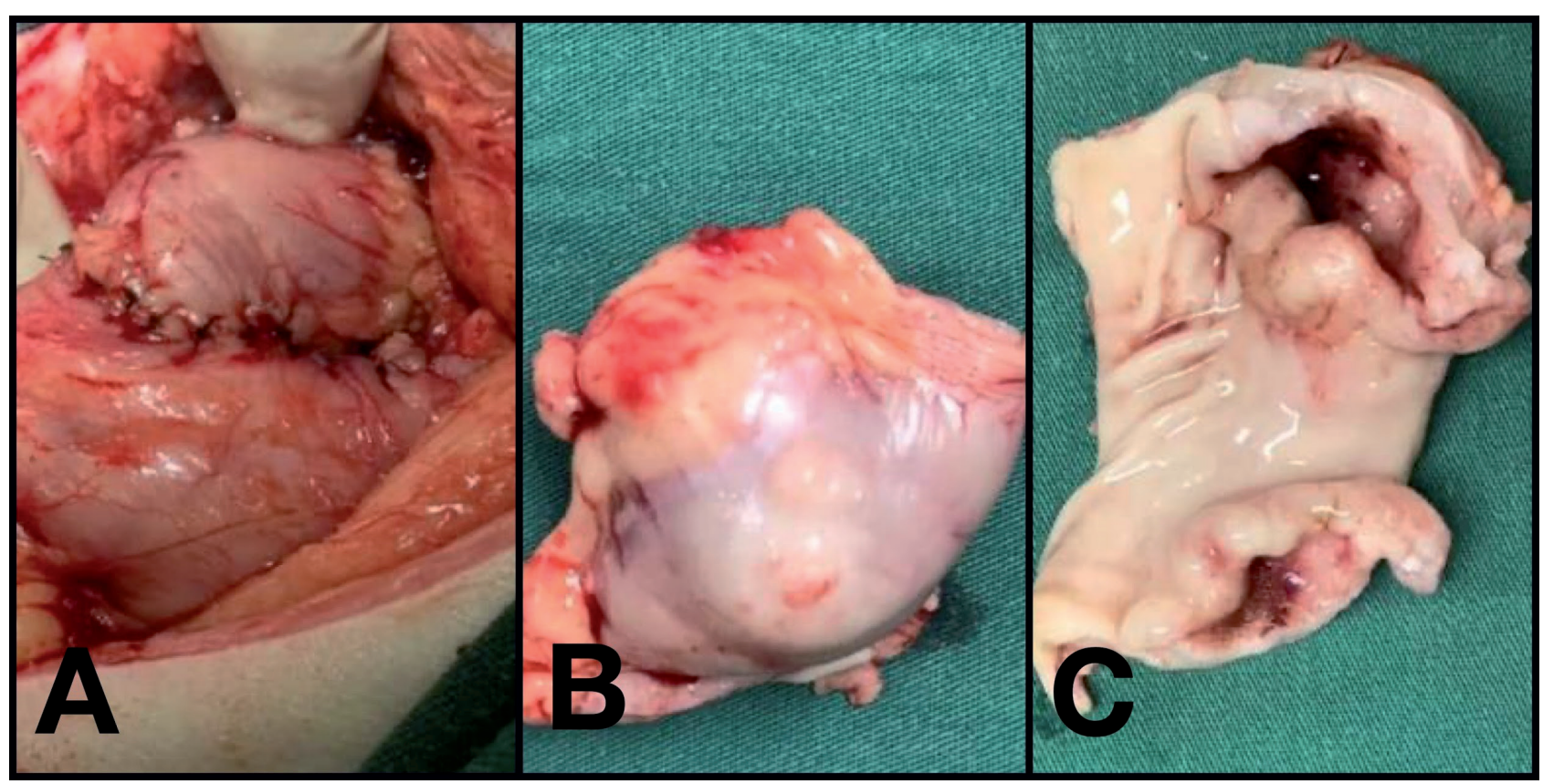

Figure 2. Trans- and post-surgical images of pylorectomy and gastroduodenostomy to remove a gastric leiomyoma in a poodle dog. A- Final aspect of the suture for gastroduodenal anastomosis, using the Billroth I technique. B- Pyloric portion with neoplasia, excised by pylorectomy. C- Transverse opening of the pyloric region over leiomyoma. 
$\operatorname{xican}^{7}(0.05 \mathrm{mg} / \mathrm{kg} / \mathrm{SID})$ as postoperative medication. Tramadol $^{11}(5.0 \mathrm{mg} / \mathrm{kg} / \mathrm{TID})$ was applied subcutaneously to increase pain control. After this initial period, the animal was discharged from the hospital, thus continuing the surgical recovery at home. In this environment, treatment continued with cephalexin ${ }^{12}(20.0 \mathrm{mg} / \mathrm{kg} /$ BID) for another seven days, dipyrone ${ }^{4}(25.0 \mathrm{mg} / \mathrm{kg} /$ TID) for another four days, and tramadol ${ }^{11}(3.0 \mathrm{mg} / \mathrm{kg} /$ QID) for another 3 days. All medications were offered orally during this phase of postoperative management.

In addition, only pasty food was offered during the first 10 postoperative days by moistening dry food (Royal Canin Gastrointestinal ${ }^{\circledR 12}$ ) with water and processing it in a blender. The amount of the mixture was supplied according to the manufacturer's specification, but the volume was fractionated and provided in 6 daily meals. It is noteworthy that despite being pasty, the food was supplied orally, without the use of gastroenteric tubes. Dry food was offered ten days after the surgical procedure.

The animal returned for clinical reevaluation on the fifteenth day. On this occasion, the animal was clinically well, with no report of vomiting nor signs of post-surgical complications. Also, the surgical wound was healed, with cutaneous sutures being removed.

Histopathological examination of the collected excisional biopsy using the histological H\&E technique revealed the proliferation of smooth muscle cells with infiltration in the submucosa, extending between the enteroendocrine cells. Smooth muscle cells were homogeneous in shape, with euchromatic pavement nuclei and ample amphophilic cytoplasm. Additionally, lymphocytic infiltrate was present in the mucosa. Masson's trichrome and picrosirius red staining evidenced no collagen fibers as the primary component of neoplasia. Therefore, the histopathological diagnosis was gastric leiomyoma.

\section{DISCUSSION}

In a retrospective study, tumors of the gastrointestinal tract and attached glands represented only $2.61 \%$ of the total casuistry among neoplasms treated between 2013 and 2017 at the University Hospital of the Federal University of Pelotas [2]. This finding corroborates with other studies, which emphasized the low incidence of gastric tumors in dogs, with an expected occurrence of less than $1 \%$ [13]. This small incidence was also ob- served at the Veterinary Hospital of the present report, where gastric neoplasia has been rarely experienced.

Moreover, the occurrence of gastric neoplasia is more common in elderly, large dogs, and casuistry was more prevalent in males [3]. However, there is an exception for small size dogs. The epidemiological data were common to this report, as the treated patient was a 9-year-old male dog.

Adenocarcinoma is the most common gastric tumors in dogs. However, there are less frequent reports of other gastric neoplasia, such as mastocytoma, plasmacytoma, and fibrosarcoma. Furthermore, gastric muscle tumors, leiomyosarcoma, and leiomyoma have a lower prevalence $[7,16]$. Thus, the unusual occurrence of gastric leiomyoma is evidenced here.

Abdominal ultrasound is indicated for diagnosing gastrointestinal disorders $[14,18]$. In this case, ultrasound was of paramount importance, being responsible for identifying alterations in echogenicity and thickness of the muscular layer of the stomach, pylorus, and beginning of the duodenum. The ultrasound findings were essential to start the search focused on the definitive diagnosis and treatment of the patient, being required the exploratory laparotomy, followed by an excisional biopsy with a wide margin and histopathological examination to conclude the diagnosis of neoplasia.

Digestive endoscopy is another examination widely used to obtain diagnoses involving the digestive system. This modality of image examination allows the obtention of relevant information regarding the integrity or pathophysiology of digestive diseases, especially those involving the mucosa. Moreover, this diagnostic method allows for obtaining biopsies [1]. In the case discussed here, the endoscopic approach did not allow great diagnostic contributions since the neoplasia remained in the muscular layer of the stomach, pylorus, and duodenum, sparing the gastric mucosa. Furthermore, not even the performed gastric biopsy allowed the visualization of atypical cells or tissues on histopathological examination. Similarly, other authors have also experienced inconclusive findings of gastric neoplasia after biopsy via endoscopy [4].

Another advantage of digestive endoscopy is its minimally invasive therapeutic application to remove a gastrointestinal foreign body, for instance. However, this therapeutic method was not applicable in this case, as it is a neoplasm, which has an indication of tumor excision. 
This endoscopic approach was also discouraged by several authors in cases that aimed at gastrectomy $[8,9,20]$.

The conventional surgery was chosen considering the therapeutic impossibility via endoscopy or laparoscopy. Pylorectomy procedures followed by the Billroth I technique was used after the exploratory laparotomy and finding of gastric tumor, as well as the non-involvement of the pancreas and bile ducts, were observed. This indication is in line with other authors, who have recommended the use of gastrojejunostomy by the Billroth II technique in cases of duodenal, pancreatic, and major and minor duodenal papilla involvement $[11,12]$. Also, a margin of one centimeter was guaranteed in the surgical procedure of pylorectomy, which meets the principles of oncological surgery, for which margins of one to two centimeters have been used in cases of benign neoplasia and three to four centimeters for malignant neoplasia $[6,11]$.

The synthesis phase is essential in surgery regardless of the operative technique, with wide implications for the result of the procedure. Absorbable monofilament suture materials are preferred for the stage of synthesis in hollow organs, as they have a low friction coefficient, induce minimal tissue reaction, and, unlike multifilament threads, they do not have capillarity [11]. Polydioxanone 4.0 was used in this case. This is one of the recommended threads, as they also have high resistance and low degradation rate of tensile strength. However, a study showed that this surgical thread could suffer instability in an acidic environment, rapidly losing its strength, while poliglecaprone 25 is resistant to an acidic $\mathrm{pH}$ environment, maintaining its properties for a longer time [11]. Despite the above, no surgical complications were observed in the case reported here due to the choice of suture material.

The most-reported expected complications due to gastrointestinal surgeries aiming at removing neoplasms are vomiting, esophagitis, anorexia, melena, hematochezia, hematemesis, necrosis with anastomosis ulceration, and, consequently, septic peritonitis. Partial or total stenosis can also be added to these possible complications, with consequent obstruction, metastasis, and recurrences, in addition to iatrogenic trauma to the pancreatic and biliary tissue [7]. In the present case, no complications such as those previously discussed were observed since the animal was clinically healthy 15 days after the procedure, feeding normally with dry food and with no reports of other postoperative complications. However, although the neoplasia was a leiomyoma, the short postoperative period did not allow us to affirm, without temporal bias, the development of metastasis or tumor recurrence.

The prognosis of patients with malignant and benign gastric neoplasia has shown highly variable survival times [10]. The survival time is six months or less in cases of malignant gastric neoplasia due to recurrences or metastases, while a good prognosis and often cure have been observed in cases of benign neoplasms after surgical resection [11]. Thus, studies have shown variations regarding the post-surgical survival time depending on the biological behavior of the neoplasia. Therefore, the type of neoplasia in this case, together with the appropriate choice of therapy and performance of the technique, was important for the good result achieved, with a favorable prognosis for the patient.

The patient was discharged without postoperative complications, evidencing the efficiency of the Billroth I technique for gastroduodenal anastomosis after pylorectomy. Moreover, this approach allows for a greater surgical margin in cases of resections of neoplasms in the antropyloric region, which has implications for the patient's prognosis, reducing the rates of recurrences and postoperative metastases.

\section{MANUFACTURERS}

${ }^{1}$ Biosintética Farmacêutica Ltda. São Paulo, SP, Brazil.

${ }^{2}$ Medley Farmacêutica Ltda. São Paulo, SP, Brazil.

${ }^{3}$ Zoetis Indústria De Produtos Veterinários Ltda. Campinas, SP, Brazil.

${ }^{4}$ Vetnil Indústria e Comércio de Produtos Veterinários Ltda. Louveira, SP, Brazil.

${ }^{5}$ Cristália Produtos Químicos Farmacêuticos Ltda. São Paulo, SP, Brazil.

${ }^{6}$ Isofarma Industrial Farmacêutica Ltda. Eusébio, CE, Brazil.

${ }^{7}$ Ouro Fino Saúde Animal Participações S.A. Cravinhos, SP, Brazil.

${ }^{8}$ Eurofarma Laboratórios S.A. Ribeirão Preto, SP, Brazil.

${ }^{9}$ Ethicon/Johnson \& Johnson do Brasil Ltda. São Paulo, SP, Brazil.

${ }^{10}$ Shalon Fios Cirúrgicos Ltda. São Luís de Montes Belos, GO,

Brazil.

${ }^{11}$ União Química Farmacêutica Nacional S.A. Embu-Guaçu, SP, Brazil,

${ }^{12}$ Royal Canin do Brasil Indústria e Comércio Ltda. Descalvado, SP, Brazil.

Acknowledgements. To Federal Institute Goiano, for supporting us to process this case report.

Declaration of interest. The authors report no conflicts of interest. The authors alone are responsible for the content and writing of the paper. 


\section{REFERENCES}

1 Acker S., Dishop M., Kobak G., Vue P. \& Somme S. 2014. Laparoscopic-assisted endoscopic resection of a gastric leiomyoma. European Jornal of Pediatric Surgery Reports. 2(1): 3-6.

2 Barboza D.V., Grala C.X., Silva E.C., Salame J.P., Bernardi A., Silva C.B. \& Guim T.N. 2019. Estudo retrospectivo de neoplasmas em animais de companhia atendidos no hospital de clínicas veterinárias da universidade federal de Pelotas durante 2013 a 2017. Pubvet. 14(4): 1-12.

3 Carvalho M.C.F. 2016. Leiomioma gástrico - relato de dois casos clínicos / Gastric leiomyoma - a report of two cases. Revista de Educação Continuada em Medicina Veterinária e Zootecnia do Conselho Regional de Medicina Veterinária de São Paulo. 14(2): 20-25.

4 Cima I., Santos A., Dazzi C.C., Machado T.P., Motta A.C., Borges J., Rodríguez R. \& Silva M.A.M. 2016. Pylorectomy and Gastroduodenostomy (Billroth I Procedure) for Obstructive Antrum Pyloric Leiomyoma in a Bitch. Acta Scientiae Veterinariae. 44(158): 1-6.

5 Cooper B.J. \& Valentine B.A. 2016. Tumors of muscle. In: Meuten D.J. (Ed). Tumors in Domestic Animals. 5th edn. Ames: Iowa State Press, pp.319-364.

6 Cornell K. 2017. Stomach. In: Tobias K.M. \& Johnston S.A. (Eds). Veterinary Surgery Small Animal. 2nd edn. Saint Louis: Elsevier, pp.1484-1512.

7 Eisele J., Mcclaran J.K., Runge J.J., Holt D.E., Culp W.T., Liu S., Long F. \& Bergman P.J. 2010. Evaluation of risk factors for morbidity and mortality after pylorectomy and gastroduodenostomy in dogs. Veterinary Surgery. 39(2): 261-267.

8 Huang L., Cui J., Wu C., Zhang B., Jiang L., Xian X., Lin S., Xu N., Cao X. \& Wang Z. 2014. Endoscopic fullthickness resection and laparoscopic surgery for treatment of gastric stromal tumors. World Journal of Gastroenterology. 20(25): 8253-8259.

9 Kosmidis C., Efthimiadis C., Anthimidis G., Vasileiadou K., Stavrakis T., Ioannidou G. \& Basdanis G. 2013. Endoscopically assisted laparoscopic local resection of gastric tumor. BMC Research notes. 6 (410): 1-4.

10 Morris J. \& Dobson J. 2001. Gastro-intestinal tract. In: Small animal oncology. Oxford: Blackwell Science Ltd., pp.127-130.

11 Radlinsky M.G. 2014. Cirurgia do sistema digestório. In: Fossum T.W. (Ed). Cirurgia de Pequenos Animais. 4.ed. Rio de Janeiro: Elsevier, pp.461-497.

12 Rasmussen L. 2007. Estômago. In: Slatter D. (Ed). Manual de Cirurgia de Pequenos Animais. 3.ed. Barueri: Manole, pp.592-641.

13 Santos M.C.F.P. \& Auler F.A.B. 2019. Doenças Gástricas. In: Jericó M.M., Andrade Neto J.P. \& Kogika M.M. (Eds). Tratado de Medicina Interna de Cães e Gatos. Rio de Janeiro: Roca, pp.967-975.

14 Silva L.C., Belotta A.F., Machado V.M.V. \& Vulcano L.C. 2013. Avaliação ultrassonográfica gástrica em pequenos animais. Veterinária e Zootecnia. 20 (4): 567-575.

15 Sturgess C.P. 2001. Doenças do trato alimentar. In: Dunn J.K. (Ed). Tratado de Medicina Interna de Pequenos Animais. São Paulo: Roca, 402p.

16 Swann H.M. \& Holt D.E. 2002. Canine gastric adenocarcinoma and leyomyosarcoma: a retrospective study of 21 cases (1986-1999) and literature review. Journal of the American Animal Hospital Association. 38 (2): 157-164.

17 Walter M.C., Matthiesen D.T. \& Stone E.A. 1985. Pylorectomy and gastroduodenostomy in the dog: technique and clinical results in 28 cases. Journal of the American Veterinary Medical Association. 187(9): 909-914.

18 Willard M.D. 2010. Distúrbios do sistema digestório. In: Nelson R.W. \& Couto C.G. (Eds). Medicina Interna de Pequenos Animais. 4.ed. Rio de Janeiro: Mosby Elsevier, pp.351-484.

19 Withrow S.J. 2007. Cancer of the Gastrintestinal Tract. In: Withrow S.J. \& Vail D.M (Eds). Small Animal Clinical Oncology. 4th edn. St. Louis: Elsevier, pp.480-483.

20 Zhang B., Huang L., Wu C., Cui J., Jiang L. \& Zheng H. 2013. Endoscopic full-thickness resection of gastric stromal arising from the muscularis propria. Chinese Medical Journal. 12(13): 2435-2439. 